\title{
Quantification of cAMP and cGMP analogs in intact cells: pitfalls in enzyme immunoassays for cyclic nucleotides
}

\author{
Katharina Werner • Frank Schwede • \\ Hans-Gottfried Genieser • Jörg Geiger • Elke Butt
}

Received: 26 April 2011 / Accepted: 8 June 2011 /Published online: 29 June 2011

(C) The Author(s) 2011. This article is published with open access at Springerlink.com

\begin{abstract}
Immunoassays are routinely used as research tools to measure intracellular cAMP and cGMP concentrations. Ideally, this application requires antibodies with high sensitivity and specificity. The present work evaluates the crossreactivity of commercially available cyclic nucleotide analogs with two non-radioactive and one radioactive cAMP and cGMP immunoassay. Most of the tested cyclic nucleotide analogs showed low degree competition with the antibodies; however, with Rp-cAMPS, 8-Br-cGMP and 8-pCPT-cGMP, a strong cross-reactivity with the corresponding cAMP and cGMP, respectively, immunoassays was observed. The determined EIA-binding constants enabled the measurement of the intracellular cyclic nucleotide concentrations and revealed a time- and lipophilicity-dependent cell membrane permeability of the compounds in the range of $10-30 \%$ of the extracellular applied concentration, thus allowing a more accurate prediction of the intracellular analog levels in a given experiment.
\end{abstract}

Keywords Cyclic nucleotides · Enzyme immunoassay Lipophilicity. Cell permeability

Electronic supplementary material The online version of this article (doi:10.1007/s00210-011-0662-6) contains supplementary material, which is available to authorized users.

K. Werner $\cdot$ J. Geiger $\cdot$ E. Butt $(\bowtie)$

Institute for Clinical Biochemistry and Pathobiochemistry,

University of Wuerzburg,

Grombuehlstr. 12,

97080 Wuerzburg, Germany

e-mail: butt@klin-biochem.uni-wuerzburg.de

F. Schwede $\cdot$ H.-G. Genieser

Biolog Life Science Institute,

Flughafendamm 9a,

28199 Bremen, Germany

\section{Introduction}

The second messengers cAMP and cGMP control a multitude of cellular processes, such as gene transcription, chemotaxis, proliferation, differentiation and apoptosis. In this regard, cAMP and cGMP enzyme immunoassays (EIA) and radioactive immunoassays (RIA) are routinely used as research tools to estimate the concentration of the cyclic nucleotides in a cell. The cAMP and cGMP immunoassays are based on the competition of free cyclic nucleotide with linked cAMP or cGMP tracer. Routinely, the cyclic nucleotide antibodies are analysed for cross-reactivity with the mono-, di- and triphosphates of several nucleotides (e.g. ADP, GTP and CTP); however, nonspecific binding of cyclic nucleotide derivatives is not determined.

In the last 30 years, a large variety of cyclic nucleotide analogs (e.g. 8-Br-cAMP, 8-pCPT-cGMP and 8-pCPT-2'-OMe-cAMP; Poppe et al. 2008) as well as purine-based phosphodiesterase inhibitors (IBMX, theophylline) have been applied to study intracellular cAMP and cGMP pathways and to manipulate cyclic nucleotide binding partners like ion channels (Craven and Zagotta 2006), protein kinases (Lohmann and Walter 2005), phosphodiesterases (Omori and Kotera 2007) and exchange proteins directly activated by cAMP (Epac; Gloerich and Bos 2010) in intact cells. Based on their purine-riboside structure, these synthetic derivatives have the potential to interfere with the cAMP- and cGMPEIAs to give false positive results. We therefore tested the most commonly applied cyclic nucleotides for their competition with the specific cAMP and cGMP antigens in two frequently used commercial EIAs in vitro and with intact cells (Horton et al. 1992). In addition, a set of systematically modified cyclic nucleotide analogs was chosen to map the epitope interaction of the polyclonal antibodies and to predict potential cross-reactivities with novel derivatives. 
Due to their polar ionic structure, cAMP and cGMP are not able to penetrate intact cellular membranes. Therefore, cyclic nucleotide analogs with lipophilic substituents are used in intact cell experiments to mimic the intracellular effects of cAMP and cGMP. However, the concentrations needed for a given cell line have to be determined laborious in dose-response experiments. On the basis of the EIA data raised in this study, we are now able to measure the intracellular concentration of extracellularly applied cyclic nucleotides and to predict the bioavailability of the derivatives in accordance to their lipophilicity index.

\section{Methods}

Cyclic nucleotide analogs

All cyclic nucleotides and derivatives (Supplementary Figs. S1 and S2) were from Biolog Life Science Institute (Bremen, Germany) and diluted in aqua dest. The PDE inhibitors 3-isobutyl-methyl-xanthine (IBMX), theophylline and erythro9-(2-Hydroxy-3 nonyl)-adenine hydrochloride (EHNA) (Supplementary Fig. S3) were obtained from Sigma-Aldrich (Deisenhofen, Germany) and diluted in DMSO.

Cyclic nucleotide enzyme immunoassay (EIA) and radio immunoassay (RIA)

For measuring cyclic nucleotide concentrations, the nonradioactive cAMP- and cGMP-EIA kits from ENZO Life Sciences (Loerrach, Germany), the cGMP-EIA from Cayman (IBL International, Hamburg, Germany) and the radioactive cAMP- and cGMP-RIA kits from IBL (Hamburg, Germany) were used following the instructions of the manufacturer. If not stated otherwise, all experiments were performed with the acetylation protocol to achieve maximum sensitivity. The yellow-coloured product formed with the EIAs is inversely proportional to the amount of cyclic nucleotide present in the sample and was detected at $405 \mathrm{~nm}$ by a multiple counter (Victor $^{2}$ Tм 1420, Wallac/Perkin Elmer, Rodgau, Germany). Radioactivity (I-125) was detected with a Berthold Counter LB 2104 (Bad Wildbad, Germany). All experiments were done three times in duplicate.

Preparation of washed human platelets

All procedures were carried out at room temperature. Blood was drawn from healthy volunteers, who gave informed consent and had been medication-free for 10 days, using venipuncture with a hollow needle into CCD-EGTA-buffer (20 mM sodium citrate, $\mathrm{pH} 6.5,1.5 \mathrm{mM}$ citric acid, $10 \mathrm{mM}$ glucose, $4 \mathrm{mM}$ EGTA, final concentration). Platelet-rich plasma was prepared by 20 -min centrifugation at $300 \times g$.
After $5 \mathrm{~min}$ rest, platelets were pelleted by 10 -min centrifugation at $380 \times g$, washed once in resupension buffer (10 mM Hepes, pH 7.4, $145 \mathrm{mM} \mathrm{NaCl}, 5 \mathrm{mM} \mathrm{KCl}, 1 \mathrm{mM}$ $\mathrm{MgCl}_{2}, 10 \mathrm{mM}$ glucose) and resuspended at a final concentration of $3 \times 10^{8}$ platelets $/ \mathrm{ml}$ (washed platelets). Platelet count was determined using a Technicon H.3 RTC blood cell counter (Bayer, Frankfurt, Germany).

\section{Cell culture}

Chinese hamster ovarian cells $(\mathrm{CHO})$ were grown on $75-\mathrm{cm}^{2}$ culture flasks in $15 \mathrm{ml}$ of Dulbecco's modified Eagle's medium (Invitrogen, Karlsruhe, Germany), supplemented with $10 \%$ foetal bovine serum and $1 \%$ penicillin/streptomycin solution (Sigma-Aldrich, Deisenhofen, Germany). Cells were maintained at $37^{\circ} \mathrm{C}$ in a humidified atmosphere of $5 \% \mathrm{CO}_{2}$ and $95 \%$ air.

\section{Cell membrane permeability}

Cell membrane permeability of cyclic nucleotides was determined by incubating $300 \mu \mathrm{l}$ washed platelets with various concentrations of cyclic nucleotides at $37^{\circ} \mathrm{C}$ for the time points indicated (normally $20 \mathrm{~min}$ ). After centrifugation $(1 \mathrm{~min}$, $720 \times \mathrm{g}$ ) and removal of the analog containing supernatant, cells were resuspended in $300 \mu$ hypertonic buffer $(10 \mathrm{mM}$ Hepes, $\mathrm{pH}$ 8.1, $10 \mathrm{mM} \mathrm{KCl}, 1.5 \mathrm{mM}$ EDTA, $200 \mathrm{mM}$ sucrose, $1 \mathrm{mM}$ IBMX) and left on ice for $30 \mathrm{~min}$. For CHO cell permeability measurements, cells were incubated with various analog concentrations in serum-free medium for the time points indicated (normally $20 \mathrm{~min}$ ), washed with PBS, covered with $300 \mu \mathrm{l}$ hypotonic buffer, left on ice for $30 \mathrm{~min}$, scraped off and transferred into a reaction tube.

Further cell disruption was done for both cell types in a freeze/thaw cycle with liquid nitrogen followed by needle disruption. After centrifugation $\left(10 \mathrm{~min}, 20.800 \times \mathrm{g}, 4^{\circ} \mathrm{C}\right)$, the cyclic nucleotide containing supernatant was lyophilized and then used in the EIA.

\section{SDS-PAGE and western blot}

Ten microgrammes of the protein extracts were separated by $9 \%$ SDS-PAGE under reducing conditions and transferred onto nitrocellulose membranes by the wet method. After blocking with $3 \%$ non-fat dry milk in $10 \mathrm{mM}$ Tris buffer, $\mathrm{pH} 7.5,150 \mathrm{mM} \mathrm{NaCl}$, and $0.1 \%(w / v)$ Tween 20 , the membrane was incubated with the $16 \mathrm{C} 2$ antibody raised against pVASP Ser-239 (PKG site) or 5C6 antibody raised against pVASP Ser-157 (PKA site; both 1:10,000, Nanotools, Freiburg, Germany) followed by incubation with horseradish peroxidase-coupled goat anti-mouse IgG (Biorad, Munich, Germany), diluted 1:5,000 and visualized by ECL (GE-Healthcare, Freiburg, Germany). 


\section{Calculations}

The binding constants were calculated according to the Hill equation:

$y=y_{\max } \cdot\left(\frac{x^{\text {slope }}}{x^{\text {slope }}+\mathrm{EC}_{50} \text { slope }}\right)+y_{\min }$

where $x$ is the concentration of cyclic nucleotide, $y$ the percentage of binding (percent $B / B_{0}$ ) and $\mathrm{EC}_{50}$ the concentration of the standard or the analogs entailing $50 \%$ binding. Binding curves were determined for each derivative with at least six different concentrations in duplicates and with platelets from three different donors. $\mathrm{EC}_{50}$ values were calculated using GraphPad Prism 4 software (GraphPad, San Diego, CA, USA). Binding constants of the cyclic nucleotide analogs were calculated by dividing the $\mathrm{EC}_{50}$ derivative concentrations by the $\mathrm{EC}_{50}$ values of the $\mathrm{cAMP}$ or cGMP standards. To define the percentage of cyclic nucleotide analog permeability, the calculated intracellular concentration was divided by the used extracellular concentration and then multiplied by the binding constant (Supplementary Tables 1 and 2).

For calculating intracellular analog concentrations, cell volumes of $5.2 \mathrm{fl}$ for platelets and $1.5 \mathrm{pl}$ for $\mathrm{CHO}$ cells were taken as a basis (Eigenthaler et al. 1992; Lu et al. 2003).

\section{Results and discussion}

\section{Epitope mapping}

A series of systematically modified cAMP and cGMP analogs (Supplementary Figs. S1 and S2) was used to map the essential molecular interactions between cAMP or cGMP, respectively, and the polyclonal antibodies supplied with the ENZO enzyme immunoassay (Supplementary Tables 1 and 2).

In solution, cAMP preferentially arranges in the anticonformation, while analogs with bulky substituents at the 8position (8-Br-cAMP) stabilize the molecule in the syn- conformation (Lassota et al. 1984). The reduced affinity of 8-Br-cAMP to the cAMP-EIA paratope indicates binding of the nucleotide to the cAMP antibody in the anti-conformation.

Due to formation of an intra-molecular H-bond between the phosphate ring and the 2-amino group, cGMP is stabilized and bound to the cGMP-EIA antibody in the syn-position. 8-Br-cGMP and 8-pCPT-cGMP further stabilize this conformation and thus exhibit stronger binding constants than cGMP.

Discrimination of cAMP and cGMP by substituents in 1- or 6-position is less pronounced as expected. Apparently, cGMP is recognized by the hydrogen bond accepting oxygen at the 6position (6-SH-cGMP and 2- $\mathrm{NH}_{2}$-cPuMP show considerably reduced binding), while the hydrogen-bond donor $\mathrm{NH}_{2}$-group at position 6 in the cAMP molecule is not involved in antibody binding (only 20\% reduced binding of cPuMP).

The Rp- and Sp-phosphorothioates (Rp/Sp-cGMPS; SpcAMPS) with an exocyclic sulphur, a substitution leading to increased size, polarisability and altered distribution of the negative charge (Frey and Sammons 1985), show a less pronounced binding than cGMP and cAMP, demonstrating the importance of the ionic interaction between antibody and cyclic phosphate moiety. Surprisingly, Rp-cAMPS (Supplementary Fig. S1, compound 7) does not show reduced binding (compare cAMP with Rp-cAMPS and 8-Br-cAMP with Rp-8-Br-cAMPS, respectively). It is concluded that the equatorial oxygen in cAMP and the corresponding sulphur in Rp-cAMPS/Rp-8-Br-cAMPS are recognized by the cAMPEIA with similar, presumably weak and non-essential molecular interactions. In contrast, the axial sulphur in Sp-cAMPS obviously generates significant steric or electrostatic repulsion in a distinct region of the binding pocket. The decreased affinities observed for $2^{\prime}$-dcAMP and $2^{\prime}$-dcGMP are conditional upon the method. The $2^{\prime}$-deoxy modification blocks the acetylation desired at this position and therefore leads to reduced assay sensitivity. Without acetylation, 2'-dcGMP shows a moderately increased binding affinity (2.2-fold) compared to cGMP in the non-acetylated cGMP-EIA, while the relative binding values for 8-Br-cGMP and 8-Br-PETcGMP were not affected (Table 1). A similar observation of reduced binding difference was made for cAMP and 2'-
Table 1 Binding specificities of non-acetylated cGMP and cAMP analogs measured with the cGMP- and cAMP-EIA, respectively, from ENZO

The $\mathrm{EC}_{50}$ values represent means (SEM) of three experiments in duplicate

\begin{tabular}{lcll}
\hline Analog & $\begin{array}{l}\text { Absolute binding } \\
\mathrm{EC}_{50}[\mathrm{M}] \text { non-acetylated }\end{array}$ & $\begin{array}{l}\text { Relative binding } \\
\mathrm{EC}_{50 \mathrm{cGMP}} / \mathrm{EC}_{50 \text { Analog }}\end{array}$ & $\begin{array}{l}\text { Relative binding } \\
\mathrm{EC}_{\text {50cAMP }} / \mathrm{EC}_{\text {50Analog }}\end{array}$ \\
\hline cGMP & $1.17 \times 10^{-08}$ & 1.00 & \\
2'-dcGMP (17) & $5.28 \times 10^{-09}$ & 2.21 & \\
8-Br-cGMP (15) & $1.83 \times 10^{-09}$ & 6.40 & \\
8-Br-PET-cGMP (22) & $1.36 \times 10^{-07}$ & 0.08 & 1.00 \\
cAMP & $4.2 \times 10^{-09}$ & & 0.22 \\
2'-dcAMP (6) & $1.9 \times 10^{-08}$ & & \\
\hline
\end{tabular}


Table 2 Relative binding specificities of cyclic nucleotide analogs measured with various cGMP and cAMP immunoassays as described under "Methods" section

\begin{tabular}{|c|c|c|c|c|c|}
\hline Analog & $\begin{array}{l}\text { Specificity ENZO } \\
\text { cAMP-EIA }\end{array}$ & $\begin{array}{l}\text { Specificity IBL } \\
\text { cAMP-RIA }\end{array}$ & $\begin{array}{l}\text { Specificity ENZO } \\
\text { cGMP-EIA }\end{array}$ & $\begin{array}{l}\text { Specificity IBL } \\
\text { cGMP-RIA }\end{array}$ & $\begin{array}{l}\text { Specificity Cayman } \\
\text { cGMP-EIA }\end{array}$ \\
\hline cAMP & 1.00 & 1.00 & & & \\
\hline cGMP & & & 1.00 & 1.00 & 1.00 \\
\hline $2^{\prime}$-dcGMP & & & 0.052 & & \\
\hline Rp-cGMPS & & & 0.0027 & 0.10 & \\
\hline $2^{\prime}-$ dcAMP & 0.034 & & & & \\
\hline 8-Br-cGMP (15) & & & 4.90 & 0.20 & 0.005 \\
\hline Rp-cAMPS (7) & 0.68 & 0.67 & & & \\
\hline 8-Br-cAMP (4) & 0.004 & 0.026 & & & \\
\hline Rp-8-Br-cAMPS (12) & 0.003 & & & & \\
\hline 6-MB-cAMP (1) & 0.004 & 0.012 & & & \\
\hline 6-Bnz-cAMP (2) & 0.006 & 0.009 & & & \\
\hline 8-pCPT-cGMP (16) & & & 2.40 & 0.30 & 0.0008 \\
\hline 8-pCPT-cAMP (5) & 0.0005 & & & & \\
\hline 8-Br-PET-cGMP (22) & & & 0.10 & 0.015 & 0.016 \\
\hline Rp-8-Br-PET-cGMPS (23) & & & 0.002 & 0.011 & \\
\hline 8-pCPT-2'-OMe-cAMP (10) & 0.0003 & 0.0066 & 0.0002 & $<10^{-4}$ & \\
\hline Sp-5,6-DCl-cBIMPS (11) & $<10^{-4}$ & 0.005 & & & \\
\hline IBMX (26) & $<10^{-5}$ & $<10^{-4}$ & $<10^{-6}$ & $<10^{-6}$ & $<10^{-5}$ \\
\hline
\end{tabular}

The analogs are ordered according to their lipophilicity (see Table 4). Specificity is expressed as $\mathrm{EC}_{50 \mathrm{cGMP}}$ or cAMP/EC 50 Analog. The absolute EC50 binding constants for acetylated cAMP in $[\mathrm{M}]$ are $7.62 \times 10^{-10}$ (ENZO) and $5.8 \times 10^{-9}$ (IBL); for acetylated cGMP in [M]: $2.27 \times 10^{-10}(\mathrm{ENZO})$, $1.8 \times 10^{-9}$ (IBL) and $3.9 \times 10^{-10}$ (Cayman)

dcAMP with the non-acetylated cAMP-EIA (Table 1). Overall, acetylation enhances the sensitivity of the EIAs but does not affect the relative binding values obtained without acetylation.

\section{Cross-reactivities}

The chemical structures of the cyclic nucleotide derivatives tested are shown in Supplementary Fig. S1 (cAMP analogs),

Table 3 Cell membrane permeability and activation constants for selected cyclic nucleotide analogs

\begin{tabular}{|c|c|c|c|c|c|}
\hline Analog & $\begin{array}{l}\text { cNMP conc. inside } \\
\text { platelets }(\% \text { of external })\end{array}$ & $\begin{array}{l}\text { cNMP conc. inside } \\
\text { CHO cells ( } \% \text { of external) }\end{array}$ & $\begin{array}{l}\text { Lipophilicity } \\
\log K_{w}\end{array}$ & $\begin{array}{l}\text { Activation }{ }^{\mathrm{b}} \text { PKG } \\
\mathrm{I} \beta K_{a}(\mu \mathrm{M})\end{array}$ & $\begin{array}{l}\text { Activation }{ }^{\mathrm{b}} \text { PKA } \\
\text { II } K_{a}(\mu \mathrm{M})\end{array}$ \\
\hline cGMP & & & 0.77 & 0.9 & \\
\hline 2'-dcGMP (17) & $0.5 \pm 0.1$ & $0.3 \pm 0.5$ & 0.66 & 21 & \\
\hline 8-Br-cGMP (15) & $12.1 \pm 3.5$ & $13.5 \pm 11.5$ & 1.17 & 1.0 & \\
\hline 8-pCPT-cGMP (16) & $19.6 \pm 4.7$ & $\mathrm{n} / \mathrm{d}$ & 2.52 & 0.9 & \\
\hline 8-Br-PET-cGMP (22) & $30.9 \pm 5.7$ & $24.1 \pm 9.7$ & 2.83 & 0.009 & \\
\hline cAMP & & & 1.09 & & 0.08 \\
\hline $2^{\prime}$-dcAMP (6) & $0.2 \pm 0.3$ & $0.1 \pm 0.2$ & 0.97 & & $\mathrm{n} / \mathrm{d}$ \\
\hline 8-Br-cAMP (4) & $\mathrm{n} / \mathrm{d}$ & $\mathrm{n} / \mathrm{d}$ & 1.35 & & 0.09 \\
\hline Sp-5,6-DCl-cBIMPS (11) & $\mathrm{n} / \mathrm{d}$ & $\mathrm{n} / \mathrm{d}$ & 2.99 & & 0.12 \\
\hline
\end{tabular}

All experiments were performed three times

$n / d$ not determined

${ }^{a}$ Krass et al. (1997)

${ }^{\mathrm{b}}$ Poppe et al. (2008) 
Supplementary Fig. S2 (cGMP analogs) and Supplementary Fig. S3 (PDE inhibitors). Dose-response curves were prepared using different concentrations of cyclic nucleotide analogs (Supplementary Fig. S4).

In the cAMP-EIA, significant cross-reactivity was observed only with cPuMP and the PKA inhibitor Rp-cAMPS (Supplementary Table 1). A similar interference was also mentioned by Grazul-Bilka and colleagues. In their study, Rp-cAMPS and dibutyryl-cAMP, both were recognized by a cAMP-RIA from DuPont/NEN (Grazul-Bilska et al. 1996). Due to its low lipophilicity, Rp-cAMPS is not frequently used for in vivo experiments; however, studies with RpcAMPS in combination with cAMP determination are reported (Fan et al. 2009).

The most prominent competitors in the ENZO cGMP-EIA with superior binding constants compared to cGMP are 8-BrcGMP and 8-pCPT-cGMP (Table 2 and Supplementary Table 2), two PKG activators frequently used in intact cells. The PKG activator 8-Br-PET-cGMP still exhibits $10 \%$ of the cGMP affinity to the antibody used in the assay. Occasionally, these compounds are used to investigate effects of PKG on PDE activity. In some studies, the measured intracellular cGMP levels are far too high and imply cross-reactivity of the applied cGMP analogs with the used immunoassays (Yoshioka et al. 2000; Bosgraaf et al. 2002). With regard to our data, the measurement of cGMP concentrations in the presence of 8-Br-cGMP or 8-pCPT-cGMP should be avoided with the ENZO cGMP-EIA, while the use of 8-Br-PETcGMP is recommended. Conversely, this kit can be used to determine cellular uptake or secretion of 8-Br-cGMP and 8pCPT-cGMP.

In consequence, we tested some of the interfering derivatives with a second cGMP-EIA (Cayman Chemical Company) and two radioactive immunoassays (IBL International). While the Cayman EIA assay is less sensitive to cGMP $(1.0 \mathrm{pmol} / \mathrm{ml})$ than the ENZO cGMP-EIA $(0.01 \mathrm{pmol} / \mathrm{ml})$, the specificity concerning cGMP analogs is superior: cGMP 1.00, 8-BrPET-cGMP 0.16, 8-Br-cGMP 0.05 and 8-pCPT-cGMP 0.0008 (Table 2). The Cayman assay is therefore advantageous when measuring cGMP in the presence of 8 -Br-cGMP and 8pCPT-cGMP.

The cAMP- and cGMP-RIA from IBL exhibit lower cross-reactivities with the selected cNMP analogs than the ENZO assays; however, binding constants in the range of $20 \%$ for 8 -Br-cGMP and $30 \%$ for 8-pCPT-cGMP with the cGMP-RIA as well as $66 \%$ for Rp-cAMPS with the cAMPRIA are still far too high for measuring cAMP and cGMP concentrations in intact cells in the presence of theses cNMP analogs (Table 2).

The two nonspecific PDE inhibitors theophylline and IBMX as well as the PDE 2 inhibitor EHNA (Supplementary Fig. S3) do not interfere with any of the tested immunoassays (Table 2 and Supplementary Tables 1 and 2) at all. Therefore, measurement of cGMP and/or cAMP is feasible even if these inhibitors are used in the millimolar range sometimes required for experiments in intact cells for efficient PDE inhibition.

Also, the Epac activator 8-pCPT-2'-O-Me-cAMP does not cross-react with either immunoassay; however, inhibition of certain phosphodiesterases by 8 -pCPT-2'-O-Me-cAMP can indirectly affect endogenous cGMP levels (Poppe et al. 2008).

\section{Cell membrane permeability}

Passive diffusion is the major route for cell permeation of most drugs and predominantly governed by lipophilicity, polarity, charge and size of the respective molecule. We have selected cyclic nucleotide analogs covering a wide range in lipophilicity ( $\log K_{w}$; Krass et al. 1997; http:// www.biolog.de/technical-info/lipophilicity-data/) and determined their cell membrane permeability with human platelets and $\mathrm{CHO}$ cells (Table 3).

For cyclic nucleotides with a molecular weight of about $350 \pm 150$, membrane diffusion without restriction is assumed

Table 4 Lipophilicity and cell membrane permeability of cyclic nucleotide analogs

\begin{tabular}{|c|c|c|}
\hline Analog & $\begin{array}{c}\text { Lipophilicity }^{\mathrm{a}} \\
\log K_{\mathrm{w}}\end{array}$ & Permeability \\
\hline $\begin{array}{l}\text { 1-NO-cAMP (9) } \\
2 ` \text {-dcGMP (17) } \\
\text { cGMP } \\
\text { 7-CH-cGMP (14) } \\
\text { Rp-cGMPS (18) } \\
\text { 2-NH }- \text {-cPuMP (21) } \\
2^{2}-\text { dcAMP (6) } \\
\text { Sp-cGMPS (19) } \\
\text { cPUMP (20) } \\
\text { cAMP }\end{array}$ & $\begin{array}{l}0.65 \\
0.66 \\
\mathbf{0 . 7 7} \\
0.81 \\
0.89 \\
0.95 \\
0.97 \\
1.02 \\
1.03 \\
\mathbf{1 . 0 9}\end{array}$ & $0 \%$ \\
\hline $\begin{array}{l}\text { 8-Br-cGMP (15) } \\
\text { 7-CH-cAMP (3) } \\
\text { Rp-cAMPS (7) } \\
\text { 6-SH-cGMP (13) } \\
\text { Sp-cAMPS (8) } \\
\text { 8-Br-cAMP (4) } \\
\text { Rp-8-Br-cAMPS (12) } \\
\text { 6-MB-cAMP (1) } \\
\text { 6-Bnz-cAMP (2) }\end{array}$ & $\begin{array}{l}1.17 \\
1.21 \\
1.21 \\
1.32 \\
1.32 \\
1.35 \\
1.47 \\
1.64 \\
1.90\end{array}$ & $\begin{array}{l}12.1 \% \\
12.2 \%\end{array}$ \\
\hline $\begin{array}{l}\text { 8-pCPT-cGMP (16) } \\
\text { 8-pCPT-cAMP (5) }\end{array}$ & $\begin{array}{l}2.52 \\
2.65\end{array}$ & $\begin{array}{l}19.6 \% \\
22.0 \%^{b}\end{array}$ \\
\hline $\begin{array}{l}\text { 8-Br-PET-cGMP (22) } \\
\text { Rp-8-Br-PET-cGMPS (23) } \\
\text { 8-pCPT-2-OMe-cAMP (10) } \\
\text { Sp-5,6-DCl-cBIMPS (11) }\end{array}$ & $\begin{array}{l}2.83 \\
2.83 \\
2.94 \\
2.99\end{array}$ & $30.9 \%$ \\
\hline
\end{tabular}

Lipophilicity is expressed as partition coefficient $\left(\log K_{w}\right)$ of the analog between methanol and water. Permeability represents percentage of intracellular measured cyclic nucleotide content as a function of external applied concentration

${ }^{\text {a }}$ Krass et al. (1997)

${ }^{\mathrm{b}}$ Bartsch et al. (2003) 
a
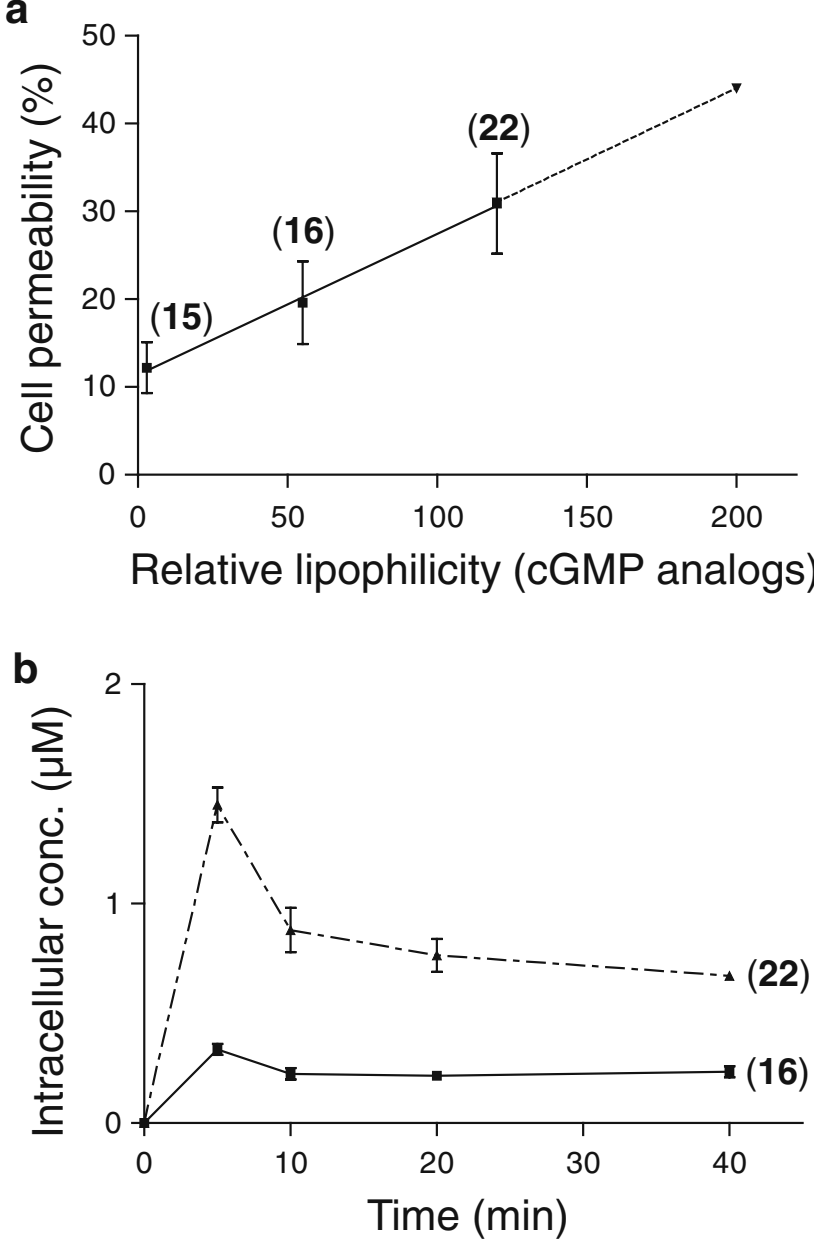

Fig. 1 a Effect of cyclic nucleotide lipophilicity on cell membrane permeability in platelets. Error bars represent SD of three independent experiments. Shown are the data for 8-Br-cGMP (analog 15), 8-pCPTcGMP (analog 16) and 8-Br-PET-cGMP (analog 22). b Timedependent influx of cyclic nucleotides. Platelets were incubated with 3nM 8-pCPT-cGMP (analog 16) or 8-Br-PET-cGMP (analog 22) for the time points indicated, and the intracellular analog concentration was measured. Error bars represent SD of two independent experiments in duplicate

(Camenisch et al. 1998). In general, the intracellular cyclic nucleotide concentrations measured confirm the expected correlation of lipophilicity and permeability (Table 4). Compounds with low lipophilicity $\left(\log K_{w}<1\right)$ are too hydrophilic for any diffusion into the cell (2'-dcGMP, $2^{\prime}$-dcAMP). At a $\log K_{w} \approx 1-2$, about $12 \%$ of the extracellularly applied cyclic nucleotide concentration is detected inside platelets and $\mathrm{CHO}$ cells (8-Br-cGMP and Rp-cAMPS). At higher lipophilicity $\left(\log K_{w} \approx 2.5\right.$ ), passive diffusion increases, and intracellular cyclic nucleotide concentration raises up to $20 \%$ (8-pCPT-cGMP) and even 30\% (8-Br-PET-cGMP; $\log K_{w}=$ 2.83 ) of the external concentration. The relative lipophilicities of the analogs calculated from the experimentally obtained log $K_{w}$ data (Table 4) correlate linearly with the amount permeated $\left(r^{2}=0.99\right.$; shown for cGMP scale in Fig. 1a).
Extrapolation of this linear approximation predicts $45 \%$ diffusion for Rp-8-Br-PET-cGMPS, a compound with $\log$ $K_{w} \approx 3$ (relative lipophilicity, 200). However, this analog does not bind to the cGMP antibody in the EIA and therefore could not be tested to substantiate/confirm this assumption. With this linear model of relative lipophilicities, the actual intracellular concentration of a cyclic nucleotide can be predicted from its known lipophilicity.

Comparable data were obtained in an earlier study analyzing cAMP analog permeation in rat $\mathrm{C} 6$ glioma cells. Incubation with 8 -Br-cAMP $\left(\log K_{w}=1.35\right)$ revealed an intracellular concentration of about $8 \%$, while the more lipophilic 8-pCPT-cAMP $\left(\log K_{w}=2.65\right)$ reached $22 \%$ of the applied extracellular concentration (Bartsch et al. 2003).

The equilibrium of inside/outside concentration of cNMPs fairly resistant to intracellular metabolism like 8-Br-cGMP (16) or 8-pCPT-cGMP (22) is achieved after 10-20 min (Fig. 1b). Longer incubation times (up to $60 \mathrm{~min}$ ) did not considerably increase the intracellular concentration of the analog (not shown). Hence, incubation times of $20 \mathrm{~min}$ are sufficient to ensure adequate loading; however, we never observed an intracellular concentration close to the external concentration (assuming a bidirectional analog passage). The molecular basis for this apparent imbalance might be explained by an active transport of cyclic nucleotide analogs from the cytosol

a

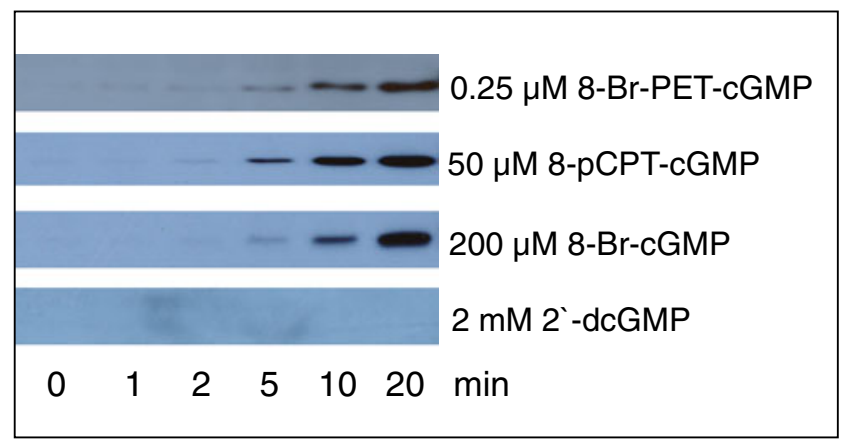

b

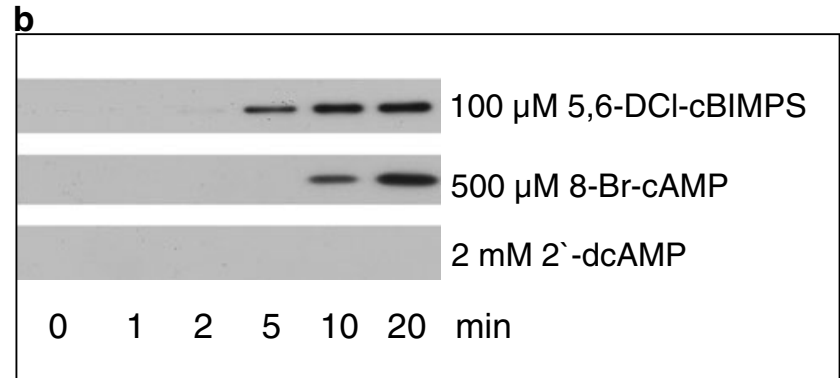

Fig. 2 Cyclic nucleotide stimulated VASP phosphorylation in intact human platelets. Cells were incubated with different concentrations of cyclic nucleotide analogs for the time points indicated. Proteins were separated by SDS-PAGE and subjected to western blot analysis for VASP phosphorylation with PKG-specific pVASP antibody 16C2 (a) or PKA-specific pVASP antibody 5C6 (b) 
into the extracellular environment (Boadu et al. 2001). This process of cellular cAMP and cGMP secretion by an apical plasma membrane transporter or by members of the multidrug resistance protein family (MRP4 and MRP5) against concentration gradients was reported in various cells like hepatocytes, vascular smooth muscle cells, epithelial cells, neuronal cells and platelets (Sager and Ravna 2009). This unidirectional ATP-activated process is analog- and concentration-dependent, and thus might explain for the observed intracellular cNMP accumulation during the first 5 min (Fig. 1b) before active extrusion commences.

Overall, the intracellular levels of externally applied cyclic nucleotides depend on more than simple membrane permeability; however, independent of the occurring membrane processes, our data depict a correlation between cNMP lipophilicity and intracellular accumulation that can be used for the design of in vivo experiments.

\section{Western blot analysis}

Western blot analysis of vasodilator-stimulated phosphoprotein (VASP), which is highly expressed in platelets, was selected to prove the correlation between lipophilicity and cell membrane permeability of cyclic nucleotide analogs. VASP is one of the most prominent substrates of cAMPand cGMP-dependent protein kinase (PKA II and PKG I $\beta$, respectively; Butt et al. 1994), which in turn are major targets of cAMP and GMP in platelets.

8-pCPT-cGMP $\left(K_{a}=0.9 \mu \mathrm{M}\right)$ and 8-Br-cGMP $\left(K_{a}=\right.$ $1.0 \mu \mathrm{M})$ show similar PKG I $\beta$ activation constants but exhibit different lipophilicities (Table 3). After $20 \mathrm{~min}$, maximal VASP phosphorylation is achieved with $50 \mu \mathrm{M} 8$ pCPT-cGMP $\left(\log K_{w}=2.52\right.$; permeability $\left.\approx 20 \%\right)$, while for 8 -Br-cGMP $\left(\log K_{w}=1.17\right.$, permeability $\left.\approx 10 \%\right), 200 \mu \mathrm{M}$ is required to achieve the same effect (Fig. 2a). For 8-Br-PETcGMP (permeability $\approx 30 \% ; K_{a}=0.009 \mu \mathrm{M}$ ), even $0.25 \mu \mathrm{M}$ are sufficient to activate PKG in human platelets (Fig. 2a). In contrast, no VASP phosphorylation is observed with 2'dcGMP $\left(K_{a}=21 \mu \mathrm{M}, \log K_{w}=0.66\right)$ at concentrations up to $2 \mathrm{mM}$ due to the lack of cell membrane permeability of this compound (Fig. 1b).

For PKA activation experiments, the compounds Sp-5,6DCl-cBIMPS and 8-Br-cAMP were selected. Both analogs exhibit similar activation constants but different lipophilicities (Table 3). To detect comparable VASP phosphorylation, only $100 \mu \mathrm{M}$ of the more lipophilic compound Sp-5,6-DClcBIMPS $\left(K_{a}=0.12 \mu \mathrm{M}, \log K_{w}=2.99\right)$ is needed, while for 8-Br-cAMP $\left(K_{a}=0.09 \mu \mathrm{M}, \log K_{w}=1.35\right), 500 \mu \mathrm{M}$ has to be applied (Fig. 2b). Similar to $2^{\prime}$-dcGMP, no VASP phosphorylation is seen with the impermeable compound 2'-dcAMP (Fig. 2b).

In summary, with the exception of Rp-cAMPS, 8-BrcGMP and 8-pCPT-cGMP, all analogs used in this study do not interfere with the tested cAMP and cGMP enzyme immunoassays from ENZO. For higher specificity, the Cayman cGMP-EIA is suggested. Overall, when assessing cAMP and cGMP levels in the presence of cNMP analogs, cross-reactivity tests with the used immunoassays used are strongly recommended.

Data acquired with immunoassays for cyclic nucleotides in the presence of cyclic nucleotide derivatives should be taken with great care, and conclusions based on these data carefully reappraised in the light of this study.

The amount of intracellularly accumulated analog was found to be $10-30 \%$ of the extracellular applied concentration, predominantly depending on the lipophilicity index of the respective compound. Experiments with cyclic nucleotide analogs in living cells should be designed, taking these observations into account. Our data provide a useful basis for scientists in the field of cyclic nucleotide regulation in living cells.

Open Access This article is distributed under the terms of the Creative Commons Attribution Noncommercial License which permits any noncommercial use, distribution, and reproduction in any medium, provided the original author(s) and source are credited.

\section{References}

Bartsch M, Zorn-Kruppa M, Kuhl N, Genieser HG, Schwede F, Jastorff B (2003) Bioactivatable, membrane-permeant analogs of cyclic nucleotides as biological tools for growth control of C6 glioma cells. Biol Chem 384(9):1321-1326

Boadu E, Vaskinn S, Sundkvist E, Jaeger R, Sager G (2001) Inhibition by guanosine cyclic monophosphate (cGMP) analogues of uptake of $[(3) \mathrm{H}] 3^{\prime}, 5^{\prime}$-cGMP without stimulation of ATPase activity in human erythrocyte inside-out vesicles. Biochem Pharmacol 62(4):425-429

Bosgraaf L, Russcher H, Snippe H, Bader S, Wind J, Van Haastert PJ (2002) Identification and characterization of two unusual cGMPstimulated phoshodiesterases in dictyostelium. Mol Biol Cell 13 (11):3878-3889

Butt E, Abel K, Krieger M, Palm D, Hoppe V, Hoppe J, Walter U (1994) cAMP- and cGMP-dependent protein kinase phosphorylation sites of the focal adhesion vasodilator-stimulated phosphoprotein (VASP) in vitro and in intact human platelets. J Biol Chem 269(20):14509-14517

Camenisch G, Alsenz J, van de Waterbeemd H, Folkers G (1998) Estimation of permeability by passive diffusion through Caco-2 cell monolayers using the drugs' lipophilicity and molecular weight. Eur J Pharm Sci 6(4):317-324

Craven KB, Zagotta WN (2006) CNG and HCN channels: two peas, one pod. Annu Rev Physiol 68:375-401

Eigenthaler M, Nolte C, Halbrugge M, Walter U (1992) Concentration and regulation of cyclic nucleotides, cyclic-nucleotide-dependent protein kinases and one of their major substrates in human platelets. Estimating the rate of cAMP-regulated and cGMP-regulated protein phosphorylation in intact cells. Eur J Biochem 205(2):471-481

Fan P, Jiang Z, Diamond I, Yao L (2009) Up-regulation of AGS3 during morphine withdrawal promotes cAMP superactivation via 
adenylyl cyclase 5 and 7 in rat nucleus accumbens/striatal neurons. Mol Pharmacol 76(3):526-533

Frey PA, Sammons RD (1985) Bond order and charge localization in nucleoside phosphorothioates. Science 228(4699):541-545

Gloerich M, Bos JL (2010) Epac: defining a new mechanism for cAMP action. Annu Rev Pharmacol Toxicol 50:355-375

Grazul-Bilska AT, Reynolds LP, Kirsch JD, Redmer DA (1996) Gap junctional intercellular communication of bovine luteal cells from several stages of the estrous cycle: effects of cyclic adenosine 3',5'-monophosphate. Biol Reprod 54(3):538-545

Horton JK, Martin RC, Kalinka S, Cushing A, Kitcher JP, O'Sullivan MJ, Baxendale PM (1992) Enzyme immunoassays for the estimation of adenosine $3^{\prime}, 5^{\prime}$ cyclic monophosphate and guanosine $3^{\prime}, 5^{\prime}$ cyclic monophosphate in biological fluids. J Immunol Methods 155(1):31-40

Krass JD, Jastorff B, Genieser HG (1997) Determination of lipophilicity by gradient elution high performance liquid chromatography. Anal Chem 69:2575-2581

Lassota P, Stolarski R, Shugar D (1984) Conformation about the glycosidic bond and susceptibility to 5'-nucleotidase of 8- substituted analogues of 5 -GMP. Zeitschrift fur Naturforschung 39(1-2):55-63

Lohmann SM, Walter U (2005) Tracking functions of cGMPdependent protein kinases (cGK). Front Biosci 10:1313-1328

Lu S, Sun X, Shi C, Zhang Y (2003) Determination of tricarboxylic acid cycle acids and other related substances in cultured mammalian cells by gradient ion-exchange chromatography with suppressed conductivity detection. J Chromatogr A 1012(2):161-168

Omori K, Kotera J (2007) Overview of PDEs and their regulation. Circ Res 100(3):309-327

Poppe H, Rybalkin SD, Rehmann H, Hinds TR, Tang XB, Christensen AE, Schwede F, Genieser HG, Bos JL, Doskeland SO, Beavo JA, Butt E (2008) Cyclic nucleotide analogs as probes of signaling pathways. Nat Methods 5(4):277-278

Sager G, Ravna AW (2009) Cellular efflux of cAMP and cGMP - a question about selectivity. Mini Rev Med Chem 9(8):1009-1013

Yoshioka A, Yamaya Y, Saiki S, Kanemoto M, Hirose G, Pleasure D (2000) Cyclic GMP/cyclic GMP-dependent protein kinase system prevents excitotoxicity in an immortalized oligodendroglial cell line. J Neurochem 74(2):633-640 